\title{
Opening the Dialogue: Reflections of my PhD Journey 2010-16
}

\author{
Debbie Hohaia \\ School of Indigenous Knowledges and Public Policy, Charles Darwin University \\ debbie.hohaia@cdu.edu.au
}

Keywords: military, Indigenous, research, methodology, institution, dialogue

\begin{abstract}
It is not an uncommon part of the human experience for casual conversations, serendipitous meetings and chance encounters to launch us in a new direction or to begin an extraordinary journey. (Bashir, 2010, p. xv)
\end{abstract}

The central aim of this paper is to highlight some of the challenges and opportunities I experienced in the field while conducting doctoral research. It focuses on some of the social and ethical issues associated with conducting research in two different Western military organisations and a remote Indigenous community in East Arnhem Land, northern Australia. Through the process of personal exploration and reflection, I seek to understand 'how and to what extent these challenges' (Barker, 2008, p. 09.1) shaped or impeded the research process and the ability to open dialogue regarding Indigenous Knowledges in military curricula. Using a decolonising lens, this paper analyses my journey in light of the methodology Institutional Ethnography, and the difficulties involved when selecting an appropriate research paradigm to suit multiple settings. It focuses on the interpersonal relationships between the researcher and participants; the strengths and limitations of insider/outsider perspectives (Barker, 2008; Innes, 2009); and the inherent roles and responsibilities of the researcher as a military employee and Indigenous woman from New Zealand.

\section{Introduction}

When I first began my PhD journey, I had little idea what the methodology might be. What I did know was that I intended to finish my doctoral research in a way that opened the dialogue between Indigenous and non-Indigenous Australians, and in ways that rejected the discourse of deficit. To bring Indigenous voices to the fore, however, working in two very different military establishments and a Yolnu community in East Arnhem Land, Australia, was never going to be an easy task. Hierarchical and bureaucratic processes combined with crosscultural research protocols made the journey particularly problematic. What it meant for me as the researcher was that I needed to choose an approach to the research that was not only acceptable in terms of the diverse groups of people that I was hoping to interview but robust enough to satisfy the ethical requirements of the Australian and New Zealand Defence Forces, as well as the university. I also wanted to challenge the 'norms' of Western research within a military context in ways that had never been considered before. Opening the dialogue to Indigenous epistemologies, ontologies and experience, became an important part of the research process. As stated by Aboriginal academic and health worker, Juanita Sherwood (2006) 'I wanted to undertake research in a manner that was safe and relevant' (p. 211). While Dorothy Smith's methodology of Institutional Ethnography seemed well suited to the task, the 
process and journey did not occur without many challenges. Institutional Ethnography allowed participants' experiences to speak as valid data, which was easily aligned with a decolonising framework. Such an approach allowed some of my own Indigenous epistemologies to guide me throughout the research process.

\section{Coming to the research table}

I grew up in Aotearoa (New Zealand) in the 1960s when many Māori families were moving to the city for employment. Known as the 'rural urban drift', New Zealand society was experiencing significant societal change at the time. Much of this change was due to an increased awareness of Indigenous people's rights, both locally and internationally, and the ensuing debate surrounding the differing interpretations of Te Tiriti o Waitangi, 1840. In education specifically, Māori students were being mainstreamed into the state schooling system where it was expected that they would 'integrate and assimilate' into the non-Māori world (Simon \& Smith et al., 2001). I was privileged in that I had been taught by many of my aunties, uncles and elders in the traditional way and in ways that respected people-place relationships and Māori customs. However, as a Māori child with strong cultural connections to Ngati Maru and Ngati Ruanui people through my paternal lineage, I very quickly learned that to survive in an urban school in the 1960s, I needed to blend in with my non-Māori peers. The need to conform to Pakeha (non-Māori) values has had a profound effect on my life. Like Indigenous academic Billie Allan (2006) describes,

What I found, was that the Anishnaabe traditions and knowledge that I had been raised with were not really welcome in the classroom. At best, my stories or suggestions were met with polite smiles or blank stares and a quick change of subject. At worse, they were met with intolerance and racism, veiled to varying degrees. (p. 258)

Being a Māori student in an urban classroom in the 1960s was like being invisible. This was of course unless I pretended to be like the Pakeha students and disguise that fact that I was Māori. Allan (2006) and Hales (2006) describe this sense of exclusion as 'epistemological racism,' which unfortunately has changed little in recent years. Despite the introduction of multi-cultural policies and diversity initiatives, there are few institutions that draw effectively from the diversities and strengths of First Nations peoples including their languages. While the choice to be educated in the city was made by my parents, the assimilationist-type education (Metge, 2008) that I received has severely impacted on my sense of belonging to the Māori world. Choosing to work in mainstream institutions and immigrating to Australia for employment in recent years has further separated me from people and place (Barker, 2008) now for almost 40 years. Although cultural identity is still extremely important to me, I consider myself to be an 'outsider' to my own community but an 'insider' in terms of my research. My doctoral research provided me with the opportunity to explore some of these issues and return briefly to my country of birth. Through critical reflection, this paper is an attempt to explore some of the benefits and implications for insider/outsider research (Innes, 2009) while working within a multi-cultural international military context.

\section{Choosing a Methodology}

One of the most difficult aspects of social research is choosing an appropriate methodology. Shawn Wilson (2008, p. 39) explains that 'the methodology is part of the paradigm that guides the research' process. Methodology is perhaps best described as the science of finding things out, or the theory of how knowledge is gained. To find things out, it was imperative that I 
considered the three different contexts in which participants were located. Because I wanted to explore the potential benefits of Indigenous Knowledges in military curricula, it made sense that I explore the New Zealand Defence Force (NZDF) first because the NZDF were well known for the success of their bicultural programs (Scoppio, 2007) and were willing to share their knowledge and experience. In many respects, the NZDF essentially 'opened the dialogue' in terms of my research. It was during this early stage that I began to understand more about research paradigms (Smith, 1999; Weber-Pillwax, 2001; Wegner, 2008; Wilson, 2008), Indigenous standpoint theories, and how to apply for the three ethics approvals required to conduct the research. While most researchers generally only have one ethics approval to contend with, the international contexts in which this research was conducted meant a total of three was required.

Towards the end of the first year, I was ready to begin the interview process. With more questions than answers, I met a chance encounter (Bashir, 2010), a work colleague of mine, who was an ex-NZDF member. Happy to assist, this colleague provided a crucial point of contact in the NZDF. Without this vital support, particularly at the initial stages, the outcomes of the research may have been far less successful. Armed with what I thought were relevant questions, I set off on a two-week study tour to New Zealand in 2013 meeting people and being immersed in the NZDF culture. As everyone knows, hindsight is always a good thing. However, as all novice researchers inevitably find out, no matter how prepared you are, even when you think you have covered everything in your data gathering instruments and theoretical understandings, nothing can quite prepare you for the reality of the research experience. Social research practitioner Earl Babbie (2007, p. 4), believes, this is because 'Reality is a tricky business'. When research involves Indigenous people, the differing concepts of reality are even more complex. For instance, it is well documented that there is a deep distrust amongst Māori communities (and Indigenous peoples more broadly) of Western research and Western research practices (Smith, 1999, p. 173). This situation has come about not only because of the unethical and disrespectful conduct of non-Indigenous researchers but because the whole 'philosophy of research and the different sets of beliefs which underlie the research process are interpreted and approached differently' from Indigenous perspectives (Smith, 1999; Wilson, 2008). Indigenous people have therefore come to realise that 'beyond control over the topic chosen for study, the research methodology needs to incorporate their cosmology, worldview, epistemology and ethical beliefs' (Wilson, 2008, p. 15). Even though my research methodology was approved by the governing institutions, the participants themselves were unable to contribute to the development of the methodology in any way, shape or form (see Hales, 2006, p. 248). As a result, some of the questions that I thought were pertinent, while sitting in my ivory tower (Barker, 2008) thousands of miles away from the participants themselves, seemed far less relevant when conducting interviews face-to-face.

As the journey progressed, it became clear that I needed to adapt the questions and approach to best suit the context. Of course, this had to be achieved without compromising my ethical responsibilities as a researcher, and/or the rights of participants. The ability to adapt the methodology to best suit the circumstance became fundamental to the success of the project (Hohaia, 2015). I also learned very quickly how important it was to have supportive contacts. Notwithstanding the usual dilemmas experienced by novice researchers, for example, changes to travel arrangements, interview timings, and 'no shows' to name just a few, momentum gathered and by the start of the second year, things started to fall into place. By way of another chance encounter, I met a whanaunga (cousin) of mine who was also conducting doctoral research in the Galiwinku Community, Arnhem Land. Indigenous networking and casual conversations (Bashir, 2010) soon resulted in meetings being arranged with Yolnu research participants for the final stages of the data gathering process. The research had taken on a 'snowball effect' (Babbie, 2007) and by the end of the third year, I was writing the 
first of multiple drafts. Keeping the dialogue open at every stage of the research provided the hermeneutic ability to articulate what it was I was trying to achieve and the ability to keep the 'final destination' in sight (Wilson, 2008, p. 39). Debriefing regularly with supervisors and contacts provided important opportunities for feedback.

\title{
Institutional Ethnography Within a Decolonising Framework
}

Despite ethical protocols and procedures being introduced into universities and research institutions in recent years, research continues to intrude into Indigenous people's lives (Smith, 1999; Wilson, 2008). Russell Bishop (2005, p. 200) illustrates this point clearly when he states:

\begin{abstract}
Despite the Treaty of Waitangi, the colonization of Aotearoa/New Zealand and the subsequent neo-colonial dominance of majority interests in social and educational research have continued. The result has been the development of a tradition of research into Māori people's lives that addresses concerns and interests of the predominantly non-Māori researchers' own cultural worldview(s).
\end{abstract}

To select a methodology that would least intrude into peoples' lives, I chose Institutional Ethnography, within a decolonising framework. Dorothy Smith (2008) terms Institutional Ethnography as a sociology for people that begins within, and works from, peoples' embodied experience. By exploring the daily realities of participants' experience, Smith (2006) and other sociologists believe they can discover how institutional practices work that transcend the local, to coordinate with the activities of others. In other words, Institutional Ethnography explores how people participate in institutional contexts to see how these experiences relate to the bigger picture. Applying a decolonising framework meant that I could consciously seek opportunities to explore participants' learning experience, both historically and contemporarily, and in relation to the wider socio-political agenda, through the analysis of experience (both Indigenous and non-Indigenous) and text. However, while a decolonising framework was always at the forefront of my mind, this did not make it easy to navigate the 'trans-cultural' perspective of the research. I needed to reflect upon and highlight the fact that I was considered an 'insider' working and viewing one institution from both within and outside of it, while viewing the second institution from an outsider's perspective, albeit with significant insider knowledge. What I found from this experience is that there is a dire need for more Indigenous academic research to be conducted from both within and outside of institutions. Such research needs to challenge the discourse of deficit, and the tendency to see diversity and difference as something that needs to be managed. One way I achieved this during the context of my work was during the data gathering stage.

As the first stage of the research was concerned with exploring the experience of learning Māori Knowledge in the NZDF, it was appropriate to address the principles of Kaupapa Māori (Māori research theory), which was incorporated into the research process wherever practicable. Graham Smith (1990) states that Kaupapa Māori research:

- Is related to 'being Māori'

- Is connected to Māori philosophy and principles

- Takes for granted the validity and legitimacy of Māori language and culture

- Is concerned with 'the struggle for autonomy over Māori cultural well-being'

Interviews, particularly with kaumatua(s), elders in the NZDF, were usually conducted after a traditional formal 'powhiri' (welcome ceremony). While this was not always possible, the preferred method of interview for all personnel was Kānohi Kitea (face-to-face). Interviews 
and the formal/informal sharing of stories and information were often followed by a short prayer and refreshments. Meeting people in person again allowed for the use of the snowball sampling technique, whereby the researcher was referred to other members of the target population group (Babbie, 2007). Being welcomed onto the NZDF marae (Māori meeting place) in the traditional way was a very moving experience. Lorina Barker (2008), a descendant of the Muruwari people of New South Wales describes a similar experience after returning home from a prolonged absence to conduct oral history research in her home community. Barker (2008) claims she felt a 'confused sense of belonging to place' and 'being disconnected to people' (p. 0.92). She wonders what strategies people employ to deal with these mixedemotions and why, and if indeed, people want to rediscover and reconnect to people and place. Linda Tuhiwai Smith (1999) explains that the need to reconnect is an important part of the decolonising process.

Gaining trust and developing strategies to deal respectfully with participants, including disclosures of negative learning experiences, were critical during the data gathering stage. It was here that I was able to draw from my own experience and the experience of being educated in different societies. In her article 'Nurturing the gifts of understanding different realities' Keiko Kuji-Shikatani (2013) explains that 'Years of living in different situations sensitized me to be respectful and first seek to understand the local protocol-the way people like to relate to each other' (p. 231). This included where participants considered contributing to the research by speaking in their own Indigenous languages. Other decolonising strategies that I was able to employ are perhaps best explained by Smith's (1999, pp. 142-162) Twenty-five Indigenous Projects, which included validating the principles of 'reclaiming, reformulating and reconstituting' Indigenous cultures and languages through the use of storytelling, connecting, and remembering. Although I worked hard to develop relationships of trust, I often felt that my inability to converse fluently in my own language and Yolnu Matha, sometimes affected the quality of conversations, despite the privilege of having access to interpreters. I often felt restricted and disrespectful from constantly rushing about from place-to-place. Limited timings and financial constraints as well as the institutional requirement to present the findings in the English language added further complexity to the mix. I needed to write and analyse participants' stories from a largely Western viewpoint, rather than from within the worldview of some of the participants. This was a colonising limitation that I constantly grappled with, despite language barriers being partially alleviated by the requirement for all New Zealand and Australian military personnel to be competent in the English language. As Jennifer Hales (2006) points out, presenting different cultural understandings and narratives from a 'Western standpoint' is problematic because it can increase the distance of the 'Self-Other hyphen'. Ensuring that data from Galiwinku Community was presented as close to possible from participants standpoint became even more important as most of these participants spoke English as their second, third or subsequent language. Meticulous editing and constant 'checking in' with the multilingual points of contact was essential to presenting the analysis in a way that acknowledged and respected participants' stories and in ways that reduced the colonial impact. Despite these shortcomings, and the stark realisation that applying a decolonising framework requires a much deeper level of understanding than I could apply in my thesis (Hales, 2006), I was constantly inspired by participants' generosity and willingness to engage. Thus, I remained committed to applying a decolonising framework, wherever I saw the opportunity, and worked hard to pose and present the research questions and answers from a critical and Indigenous standpoint (see Hales, 2006; Smith, 1999; Wilson, 2008). 


\section{Interpersonal Relationships and Insider/Outsider Perspectives}

The importance of interpersonal relationships and insider/outsider perspectives in academic research should not be underestimated (Innes, 2009). The ability to move simultaneously from and insider to outsider (Kikumura, 1998, p. 142) provided a distinct advantage (Barker, 2008 , p. 09.6), which allowed me to work both intuitively and reflexively. For example, having an insight into the journey to include Māori Knowledge in New Zealand institutions, and the NZDF provided an important background of which I had some historical understanding. Being absent from place for over a decade, however, meant that I was being invited into the institution as an 'outsider' and could observe things that, had I been an 'insider', I might have missed (Innes, 2009). The research was conducted on three various levels: one as an Australian military member conducting individual study (insider perspective); two, having an insight into education and the military in New Zealand (insider/outsider perspective); and three, as an outsider to Galiwinku Community. I needed to remain cognisant of the researcher's responsibilities and the worldviews of each group (Innes, 2009), and regularly reflect and critique my own ontological position to keep the research in context (Wegner, 2007; Wilson, 2008). While I considered myself to be both an insider and outsider at various times, the ability to adapt quickly to new surroundings helped me find something in common with research participants to engage in a conversation' (Kuji-Shikatani, 2013, p. 231).

As a current Australian serving member, one of the advantages was that I could navigate some of the complex military processes as an insider. Like Barker (2008) who was conscious of 'family alignments and associations and privy to information and knowledge' while conducting research in her home community, I was recognised as someone who had shared part of the New Zealand bicultural journey. This made it easier for me to relate to the NZDF participants, with regards to historical, educational, military and marae protocols, although there was a perceived or assumed level of knowledge, such as te reo (language) Māori, where I had many gaps. During one interview with a kaumatua, for example, it was assumed that I was fluent in te reo. While I could understand some of what was being said, the esteemed elder soon realised that I was struggling to keep up with the conversation, and very humbly he switched to English. I will never forget the shame of not being able to converse competently in my own language, however, felt that this was one way in which I was being acknowledged as an 'insider'.

Another example of being acknowledged as an insider arose when I was interviewing another kaumatua. We had been engaged in conversation for quite some time, when at the end of the discussion I realised I had not provided the consent form. I asked the kaumatua if he would sign the form when waving the form away he said, 'why do I need to sign that, I've given my consent already by agreeing to talk to you ... I trust you'. While I managed to get the signature, as required by the research protocols, I understood the reluctance on the part of the elder to sign it. The form was likely seen as an instrument of continued oppression, reducing the kaumatua's autonomy, and therefore was part of the colonial legacy. I was given the distinct impression that the decision to talk to me should be his and his alone and should not be governed by external institutions. This was not the only occasion this happened but was repeated by elders in Galiwinku Community. Ironically, ethical practices such as signing consent forms were largely introduced by Western academics trying to protect Indigenous people from the unethical practices of predominantly non-Indigenous researchers (see the irony of this situation in 'Coyote's story', Wilson, 2008, p. 17). Linda Tuhiwai Smith (1999) reiterates this point when she writes 'Insider research has to be as ethical and respectful, as reflexive and critical, as outsider research' (p. 139).I carried this responsibility throughout the research process, consequently making myself sick with worry that I would not be able to live up to the elders', nor the institutional, requirements and expectations. 
As an outsider to Galiwinku Community, I was acutely aware of the things that made me an outsider (Barker, 2006; Smith, 1999). Not only was I a stranger to the community, but I also had no vested interest in the community in that I was not working or living there. I was simply visiting my whanaunga, who kindly introduced me to some of the elders. I also had a secondary connection to some of the community military members. Their willingness to support me as an outsider (or stranger) was how I was taught by my own elders. For example, during one session, I was invited to sit on country at a special place when the elders wanted to show me some of the significant story sites. This was a profound experience that I will never forget. It was similar to how my own elders connected me to our place-based knowledge systems and the understanding that these systems can only be taught through using all of the senses, e.g. sight, sound, place, smell, touch and the spiritual familial connection to ancestors, environment and the greater cosmos. I hope that I have provided credit to their stories in my thesis and have since been able to reciprocate their kindness by sharing meals together, when they have visited Darwin. Linda Tuhiwai Smith (1999) states of this type of relationship: 'These were signs of respect, the sorts of things I have seen members of my communities do for strangers and the practices I had been taught to observe myself' (p. 138). Arbon (2008) also refers to drawing on all spiritual relationships and one's senses within research.

\section{The Role of the Researcher}

Conducting $\mathrm{PhD}$ research from within my own organisation came with its unique advantages and disadvantages. One of the advantages was that the driving passion to complete the project came from within and was something that I was committed to, to open the dialogue for positive change. Having a vested interest, including access to systems, processes and potential participants made the journey relatively unproblematic, although difficulties arose at certain times for several reasons. For example, as an individual conducting personal research, opposed to being funded by the organisation, I needed to use my own funds and time to travel to where participants were best located. Throughout the research, I also noticed that there were certain people, or groups of people, who became personal mentors (Barker, 2008), while others seemed to challenge the validity and relevance of what I was doing. At times, there even appeared to be unnecessary hurdles to jump over and certain individuals who acted as 'institutional gatekeepers'. While these processes and people were few and far between, they suggest resistance to change, or unfamiliarity with critique from an 'insider/outsider decolonising' perspective. I was also made painfully aware that my work could be revoked at any time if it was perceived detrimental to organisational values. I encountered unrelated but equally potential work-stopping dilemmas on at least two occasions. Thus, one of my supervisors, an ex-military officer, constantly reminded me, 'we always knew that your work would be closely monitored' (personal comms. Dr David Bennett, 2016). However, it was at times like these that I could draw on the supportive network of some of my closest colleagues and supervisors, to whom I will remain forever indebted. My inner belief that the work was important, the strengths of my ancestors, and the use of the Indigenous academic fraternity was fundamental to completing the thesis.

\section{Results and Discussion}

Notwithstanding the highlighted issues of insider/outsider research and the challenges involved in conducting institutional research across two very different military organisations and a remote Indigenous community in East Arnhem Land, to be retained as an employee one of the most important lessons that I learned was that I needed to understand how my work would be interpreted by others. What I discovered was that credible research needs to explore, describe 
or explain an area that is either new, or worthy of exploration; but more important than that, it needs to hold agency for the people and organisations concerned. Robert Innes (2009) sums up these phenomena well when he states:

My research experience mirrors the experience of other insider researchers. Like Gilbert, I found that my lived experience did not exactly match that of many of the research participants. But like other insiders I was able to navigate a research relationship that enhanced my insider status in a way that allowed the research participants to accept me as an insider despite those factors that made me an outsider. The notion that researchers should distance themselves from their research participants does have some merit, as the researchers should be careful not to undermine their research aims. Yet at the same time my "closeness" to the research participants aided my gaining both their trust in me and their interest in the project. (pp. 456-7).

Like Innes (2009), who expressed that the 'closeness' to some of his participants had enabled him to gain their trust, my own insider/outsider perspectives allowed me to interact intuitively and respectfully when working with participants. My research is only one example of how to work from an institutional decolonising framework within and external to two multi-cultural military organisations and is not meant to be 'definitive'. Instead, it is meant to provide a pathway for the many possibilities that can occur when research moves outside of Western norms, and in ways that seek to validate the issues that really matter to Indigenous and nonIndigenous people. If 'we,' as the next generation of researchers, are committed to making a difference, then we must seek out the sites where continued oppression and the silencing of Indigenous voices and languages reign. In doing so, we must reflect and respond to our own work, and the work of others, and ask how our work has brought credit to the Indigenous participants concerned? If, in answer to that question it has not, then chances are, we are perpetuating continued inequity.

\section{Conclusion}

The methodological, social and ethical questions and concerns that arose during the conduct of my research have strengthened me as a researcher. By sharing this paper, as Barker (2008, p. 09.8) has so aptly quoted: 'I have revealed a small part of my journey in a personal story of the challenges, interspersed with a few moments of success'. It is hoped that this will assist other researchers to reflect on some of the relationships and experiences they have encountered during the conduct of their work. On that note, it seems pertinent to close the dialogue as it began in the words of Bashir (2010): 'It is not an uncommon part of the human experience for casual conversations, serendipitous meetings and chance encounters to launch us in a new direction or to begin an extraordinary journey' (p. xv). 


\section{References}

Allan, B. (2006). 'Remembering, resisting: casting an anti-colonial gaze upon the education of diverse students in social work education' in Dei, GJS, \& Kempf, A 2006, (eds.), Anti-colonialism and education: The politics of resistance (pp. 257-269). Rotterdam, The Netherlands: Sense Publishers.

Arbon, V. (2008). Arlathirnda, Ngurkurnda Ityrnda, Being, Knowing and Doing; De-Colonising Indigenous Tertiary Education. Teneriffe, QLD: Post Pressed.

Babbie, E. (2007). The practice of social research. California, USA: Thomsom Wadsworth.

Barker, L. (2008). 'Hangin' out' and 'yarnin': Reflecting on the experience of collecting oral histories. History Australia, 5(1), 9.1-9.10.

Bashir, M. (2010). Foreward. In A. Sarzin \& L. Sarzin (Eds.), Hand in hand: Jewish and Indigenous people working together. Sydney: NSW Board of Deputies.

Bishop, R. (2005). Freeing ourselves from neo-colonial domination in research: A Kaupapa Māori approach to creating knowledge. In N. K. Denzin and Y. S. Lincoln (Eds.), The SAGE Handbook of Qualitative Research (3rd Edn.) (pp. 109-138). Thousand Oaks, CA: Sage.

Hale, J. (2006). An anticolonial critique of research methodology. In G. J. S. Dei \& A. Kempf (Eds.), Anticolonialism and education: The politics of resistance (pp. 243-256). Rotterdam, The Netherlands: Sense Publishers.

Hohaia, D. (2015). In search of a decolonised military: Māori cultural learning experiences in the New Zealand Defence Force. Kōtuitui: New Zealand Journal of Social Sciences Online, 11(1), 47-58.

Innes, R.A. (2009). Wait a second. Who are you anyways? The insider/outsider debate and American Indian studies. American Indian Quarterly, 33(4), 440-461.

Kikumura, A. (1998). Family life histories: a collaborative venture. In R. Perks \& A. Thompson (Eds.), The oral history reader (pp. 140-144.). London: Routledge.

Kuji-Shikatani, K. (2013). Nurturing the gift of understanding different realities. In D. M. Mertens, F. Cram, \& B. Chilisa, Indigenous pathways into social research: voices of a new generation (pp. 219-237). Walnut Creek, CA: Left Coast Press.

Metge, J. (2008). Māori education 1958-1990: A personal memoir. New Zealand Journal of Educational Studies, 43(2), 13-28.

Scoppio, G. (2007). Diversity in military organizations: Indigenous peoples in the New Zealand Defence Force and the Canadian Forces, 1-18, viewed 25 April 2011, via http://www.deomi.org/ EOEEOResources/documents/Diversity_and_Culture_in_the_Military-Scoppio.pdf

Sherwood, J. (2006). An anti-colonial critique of research methodology. In G. J. S. Dei \& A. Kempf (Eds.), Anti-colonialism and education: The politics of resistance (pp. 203-217). Rotterdam, The Netherlands: Sense Publishers.

Simon, J. \& Smith, LT. with Cram, F. Hohepa, M. McNaughton, S. Stephenson, M. (2001). A civilising mission: Perceptions and representations of the New Zealand Native Schools Systems. Auckland, NZ: Auckland University Press.

Smith, D. E. (1999). Writing the social: Critique, theory and investigations. Toronto, Canada: University of Toronto Press Incorporated.

Smith, D. E. (2006). Institutional ethnography as practice. Toronto, Canada: Rowman \& Littlefield Publishers, Inc. 
Smith, D. E. (2008). Institutional ethnography. In L. M. Given (Ed.), The SAGE Encyclopaedia of Qualitative Research Methods (pp. 434-437). Viewed 14 November 2014, via http://dx.doi.org/10.4135/9781412963909

Smith, G. H. (1990). Research issues related to Māori education. Paper presented to NZARE Special Interest Conference, Massey University. Reprinted in 1992 in, The issue of research and Māori, Research Unit for Māori Education, University of Auckland.

Smith, L. T. (1999). Decolonizing methodologies: Research and indigenous peoples. London; New York: Zed Books Ltd; Dunedin, NZ: University of Otago Press.

Weber-Pillwax, C. (2001). Coming to an understanding: A panel presentation - what is indigenous research? Canadian Journal of Native Education, 25(2), 166-174.

Wegner, A. (2007). Relationships with many facets: Unpacking the interactions between protected area managers and commercial tour operators (PhD). Perth, WA: Murdoch University.

Wilson, S. (2008). Research is ceremony: Indigenous research methods. Black Point, N.S.: Fernwood Publishing. 